\title{
HUMIDITY INTRUSION EFFECTS ON THE PROPERTIES OF SOUND ACOUSTIC OF AUTOCLAVED AERATED CONCRETE
}

\author{
Abdullah Keyvani ${ }^{1}$, Sasan Somi ${ }^{2}$, Özgür Eren $^{3}$ \\ ${ }^{1}$ Assistant Professor, Azarbaijan Shahid Madani University, Iran \\ ${ }^{2}$ Graduated Student, ${ }^{3}$ Associate Professor, Eastern Mediterranean University, Cyprus
}

\begin{abstract}
Autoclaved Aerated Concrete (AAC) has been commonly known to exhibit favorable thermal properties, high fire resistance and high compressive resistance at relatively low density. However, little attention has been devoted to the sound insulation performance of AAC. One of the points needs to know is humidity intrusion effects on AAC members in areas with high relative humidity levels of Mediterranean climates which are important in durability and insulation properties of AAC. Tests on mechanical and physical properties of ACC carried out to study humidity intrusion effects on AAC members were studied with and w/o coatings on the surfaces. From the findings of this study, physical and mechanical autoclaved aerated concrete evaluated in three different humidity levels to compare the effect of humidity on properties of AAC. According to test results coating is the most important factor for improving resistivity of $A A C$ walls, and these factors help AAC walls to keep their mechanical and physical properties against humidity. With its closed air pockets, AAC can provide very good sound insulation. This paper presents the results of studies on acoustic properties of AAC partitions aimed at identifying the effect of specific factors on AAC sound insulation performance.
\end{abstract}

Keywords: AAC, concrete, humidity, sound acoustic, decibel

\section{INTRODUCTION}

Autoclaved aerated concrete (AAC) offers specific favorable properties in the context of sustainable development in the construction industry. AAC production technologies are energy-efficient and consume low quantities of raw materials as compared to the production of other construction materials, which can be attributed to low density and a special waste-free and environmental friendly production formula of AAC, [1]. Typical AAC density is between 300 and $1,000 \mathrm{~kg} / \mathrm{m} 3$ (in a dry condition). Aerated concrete has no coarse aggregates in its mixture, and it can be mentioned that aerated lightweight concrete is the concrete mortar which is aerated with fine and small bubbles from a chemical process or by using air entraining agent. Autoclaved aerated concrete is made of cement, silica sand, quick lime \& gypsum and aluminum powder [2].

The positive acoustic properties of autoclaved aerated concrete as such can be attributed to its internal structure, however, its density is relatively low, which is why the sound insulation performance of AAC partitions can be worse than that of walls of the same thickness made of other materials (e.g. normal concrete, etc.) [3].

Sound insulation requirements for internal and external walls differ considerably and depend on the location and intended use of the buildings and of the building interiors. Therefore, these diverse requirements must be taken into consideration in the evaluation of sound insulation performance of AAC walls.
Sound insulation performance of single-leaf walls made of aerated concrete can be considered sufficient in a number of applications. In exceptional circumstances, when special requirements on sound insulation performance, special materials and structural solutions need to be applied which exhibit better acoustic properties. This problem can be only solved by conducting suitable tests.

In the period 1990-2010, the studies on the development of improved acoustic properties have been considerably intensified $[4,5]$. This study is based on evaluating humidity intrusion effects on the sound acoustic properties of AAC.

\section{EXPERIMENTAL PROCEDURE}

Experiments were carried out in order to investigate sound acoustic and humidity intrusion effects. This section includes briefly descriptions about experimental procedure of tests which were carried out according to TS pr EN [6] and ASTM [7].

\subsection{Sound Acoustic Test}

Sound acoustic tests were carried out for evaluating acoustic properties of AAC panels under three different humidity conditions. For these tests, special chamber made of galvanized steel plates with dimensions of $700 \times 850 \times 600 \mathrm{~mm}$. Distance between the two steel panels of chamber was filled with lightweight material and gypsum mortar to increase its insulation capacity. 


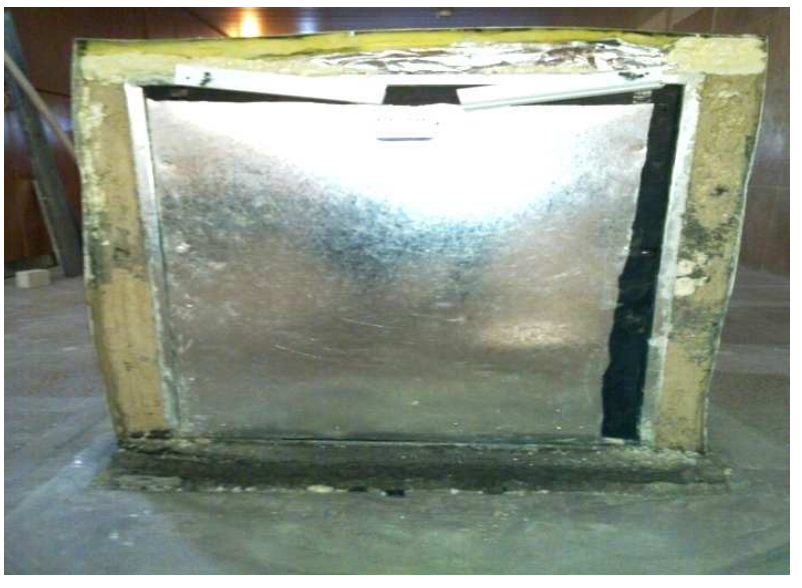

Fig-1: Outside view of the sound test chamber

Sound level meter with accuracy of $0.1 \mathrm{db}$ was used to measure frequency of sound at both inside and outside of chamber. A humidity meter was used to measure the humidity level inside the chamber. Speakers were used to produce sound inside the chamber which was connected to a computer for sound production with homogenous frequency. Plastic funnel was used to focus exited noise and reduce environments disturbing noises which cause faults in the measurements.

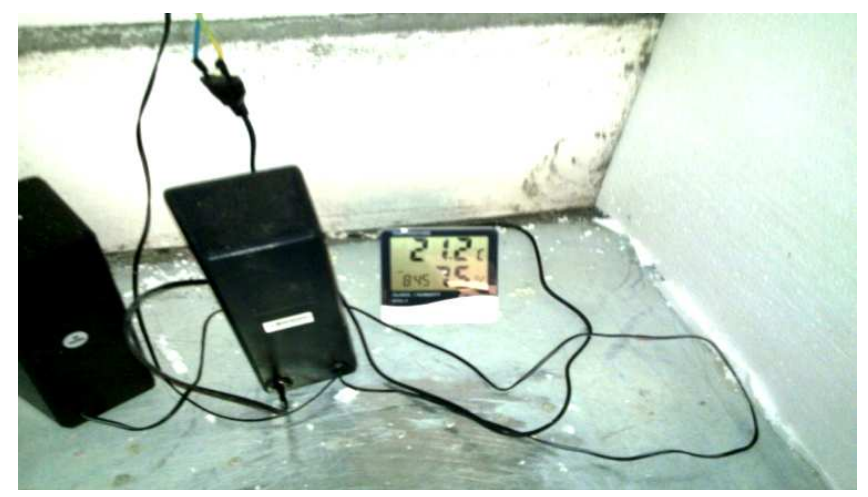

Fig-2: Set up of apparatus inside of the chamber

Measuring sound levels inside the chamber was the first step of test and a digital camera with flashlight was used inside the chamber to record data from sound level meter. Different sound levels were set from computer and ten levels were inserted in the chamber changing from $55.4 \mathrm{~dB}$ up to $87.5 \mathrm{~dB}$. Sound levels were measured outside and inside of AAC wall to determine loss of sound transmission.

Sound acoustic tests were carried out in two important cases for targets of this research:

1) Three different humidity conditions were set for AAC walls. Different humidity conditions in the chamber were created by using a vaporizer apparatus.
2) Effect of coating on acoustic properties of AAC walls was studied with a gypsum coating with a thickness of $10 \mathrm{~mm}$.



Fig-3: Sound level measuring test process

\section{RESULTS AND DISCUSSION}

Sound insulation tests were carried out on AAC panels under three different humidity conditions to determine effects of humidity on acoustic properties of AAC. Measuring sound transition loss (TL) was the main purpose of sound insulation test.

Although density and stiffness are the most important factors affecting sound transmission losses of partitions and floors, humidity can also be a factor which can affect sound transmission. According to technical report CBD-239, "in a double layer assembly, such as gypsum wallboard on wood or metal framing, the depth of air spaces, the presence or absence of sound absorbing material, and the degree of mechanical coupling between layers critically affect sound transmission losses and the sound transmission class (STC)" [8].

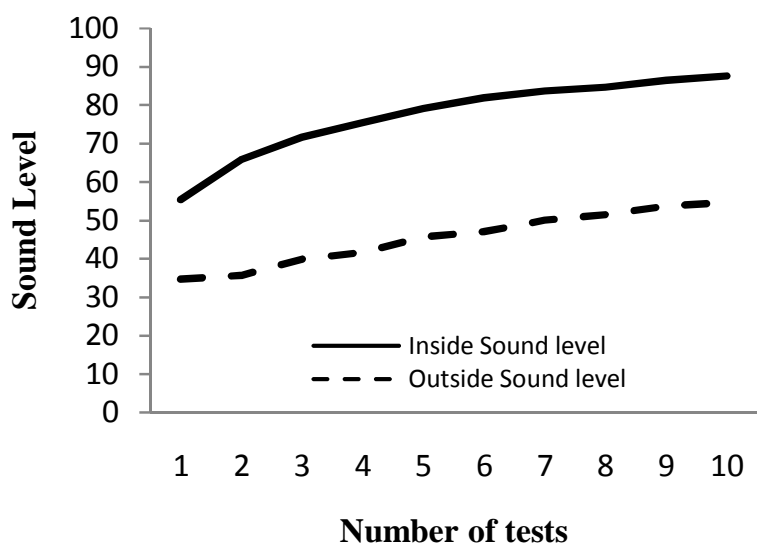

Fig-4: Sound transmission loss at 55\% humidity condition for AAC panel without coating 


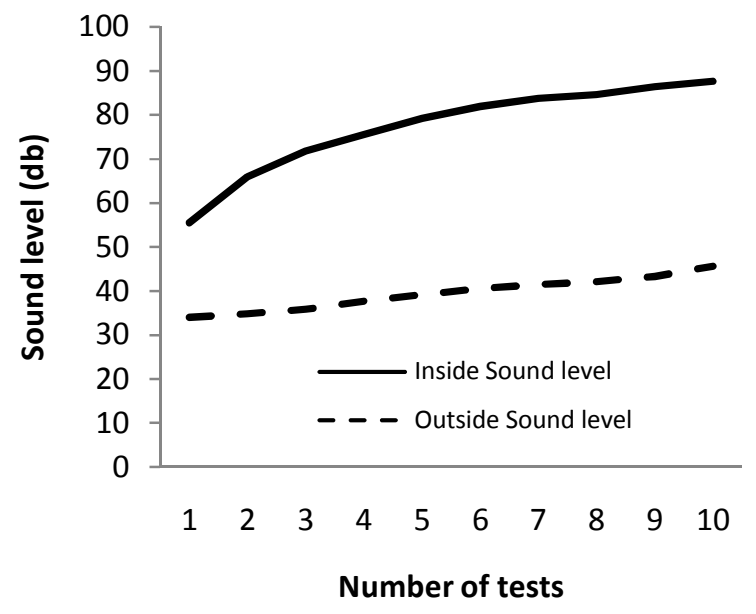

Fig-5: Sound level transmission loss at 55\% humidity condition for AAC wall with coating

AAC wall with $55 \%$ humidity level without coating were tested from $55.4 \mathrm{~dB}$ to $87.6 \mathrm{~dB}$. Results obtained for sound insulation test on AAC wall without coating shows; sound levels outside the chamber were reduced by $41.08 \%$ comparing to sound levels inside of it. In the same test conditions results obtained for AAC wall with gypsum coating in $55 \%$ humidity condition shows $48.88 \%$ sound transmission loss. When inside humidity condition was about $75 \%$, sound levels outside the chamber were measured for AAC wall without coating to determine effect of humidity condition on sound transmission loss of AAC.

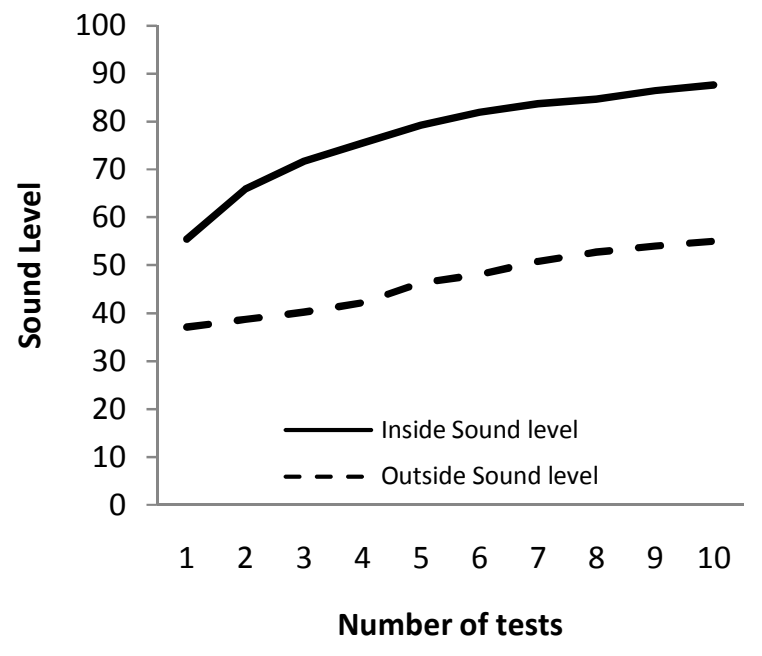

Fig-6: Sound transmission loss at $75 \%$ humidity condition for AAC wall without coating

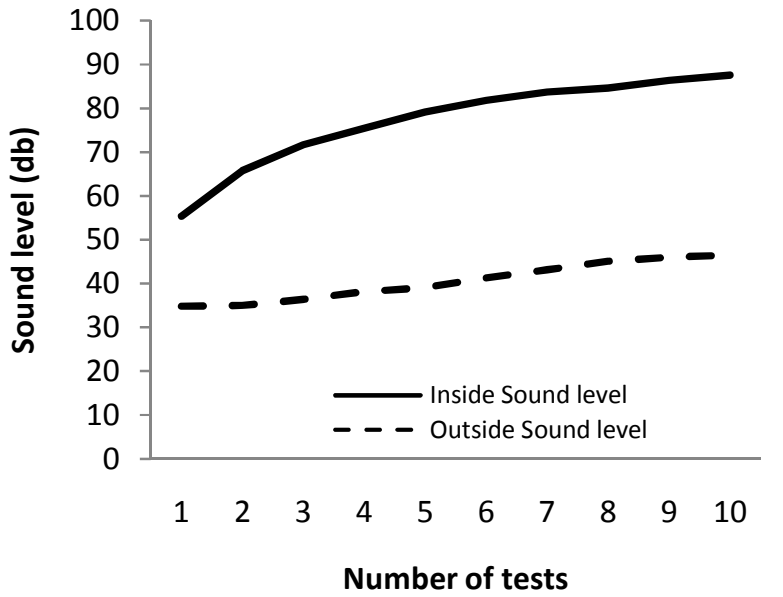

Fig-7: Sound transmission loss at $75 \%$ humidity condition for AAC wall with coating

At $75 \%$ humidity condition, sound levels inside the chamber were tested from $55.4 \mathrm{~dB}$ to $87.6 \mathrm{~dB}$. According to the results, sound levels outside the chamber were reduced compared to inside sound levels with average percentage of about $39.74 \%$ by using AAC wall without coating. After applying gypsum coating on AAC wall, an average sound transmission loss of $47.46 \%$ was obtained for the same sound levels inside the chamber which were used in pervious tests. With increasing humidity condition inside the chamber up to $100 \%$, sound levels outside the chamber were reduced compared to inside sound level with average percentage of about $37.28 \%$ by using AAC wall without coating. With applying gypsum coating on AAC wall an average sound transmission loss of $46.02 \%$ was obtained for the same sound levels inside the chamber which were used in pervious tests.

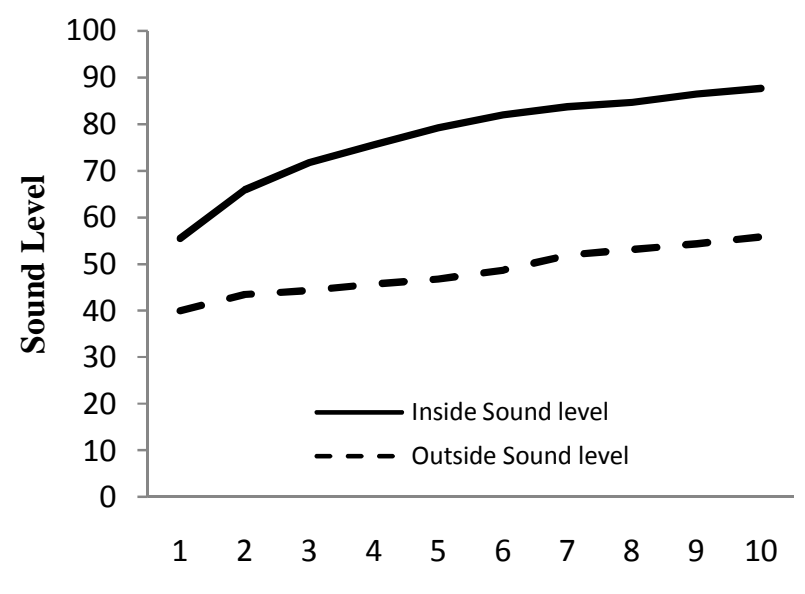

Number of tests

Fig-8: Sound transmission loss in $100 \%$ humidity condition for AAC wall without coating 


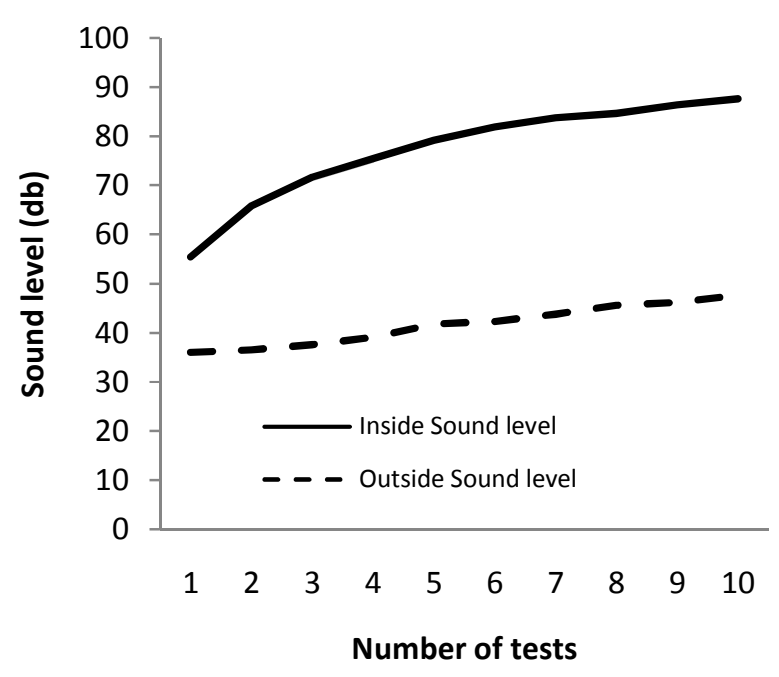

Fig-9: Sound transmission loss in 100\% humidity condition for AAC wall with coating

According to test results, average sound transmission losses of $37.28 \%$ to $48.88 \%$ were obtained by using AAC wall in different humidity conditions of $50 \%$ to $100 \%$, respectively. Test results indicated that humidity has intrusion effect on sound transmission of AAC walls.

Sound waves travel faster in dry air than moist air, because dry air is more dense than humid air and air molecules have higher mass than average water molecules. This effect of humidity on sound speed caused decreasing in sound transmission loss of AAC walls. To counteract this effect, gypsum coating was used. Results showed that humidity was less effective on the acoustic properties of AAC wall with coating and effect of gypsum coating in sound transmission loss was about $10 \%$ on average.

Since AAC is lightweight material with porous structure both coating and non-coating have beneficial effects on sound transmission loss because of increasing in air flow resistivity [8].

Results indicated that for different sound levels, sound transmission losses change parallel to sound levels inside the chamber and it is understandable that there is no resonance in acoustic properties of AAC walls.

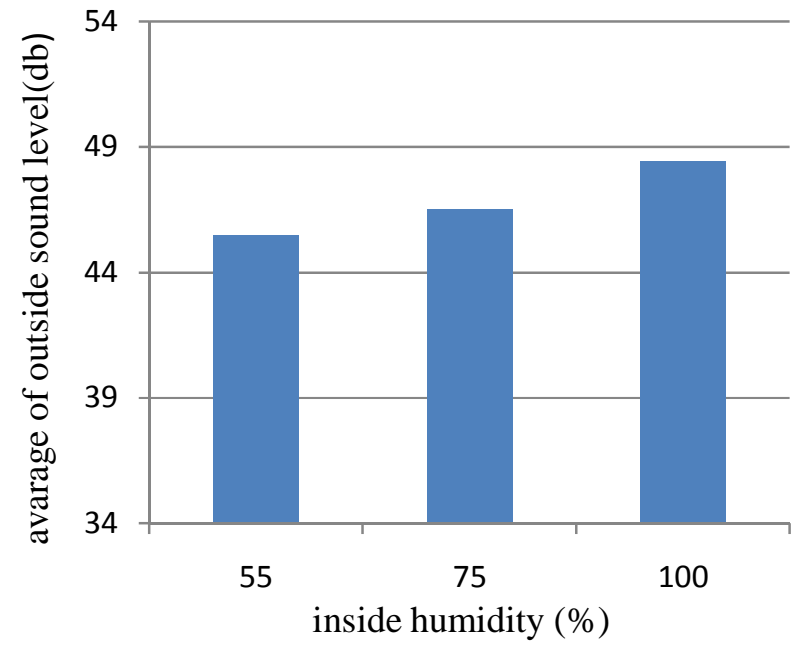

Fig-10: Effect of humidity on outside sound levels for AAC wall without coating

As indicated the plaster on aerated concrete walls with tongue and groove joints has specific sound insulating properties. Aerated concrete was also confirmed to transmit sound, even at higher densities, which means that the sound insulation performance of plaster-free walls is lower than that of plastered brickwork, even when the joints are filled with mortar. The difference in the values of sound reduction indices is considerably higher than what would be implied by the increased surface density (mass per unit area) of the plastered wall.

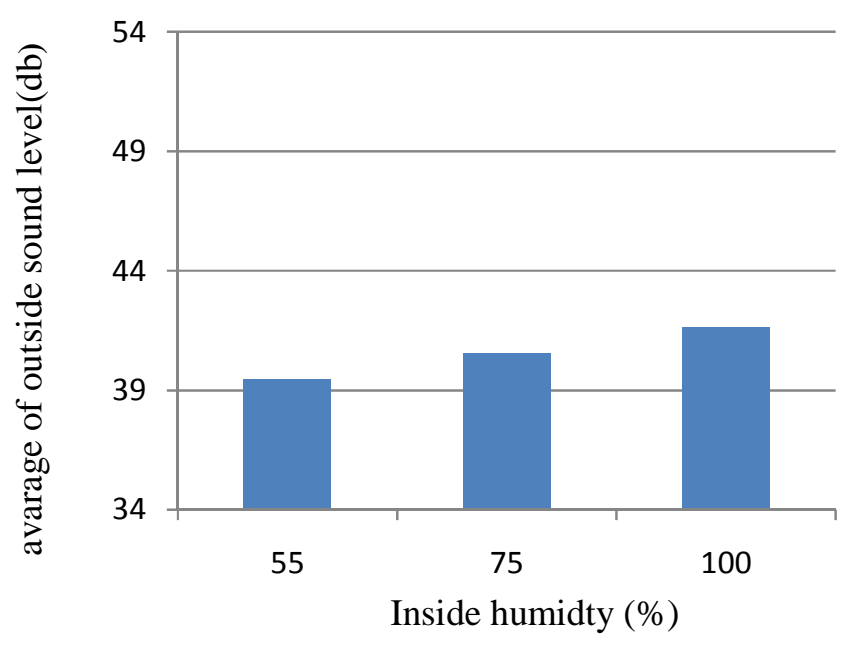

Fig-11: Effect of humidity on outside sound levels for AAC wall with coating 


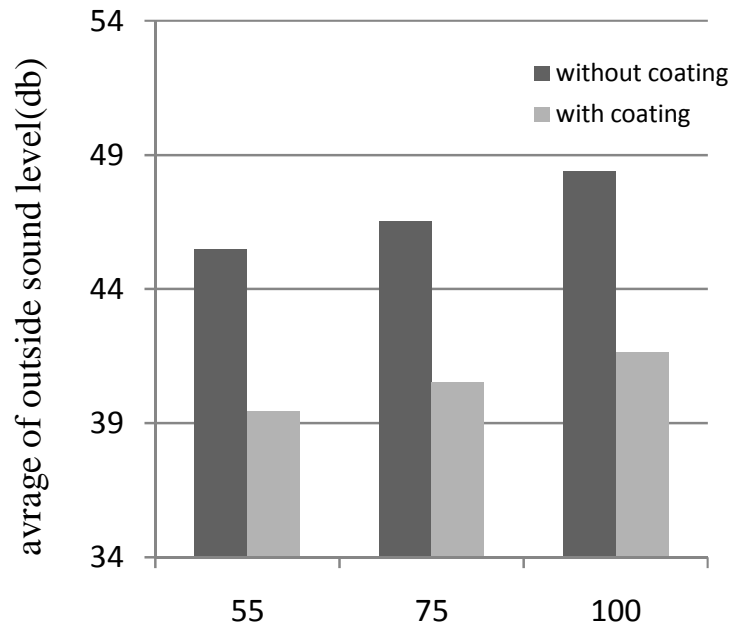

Inside humidity (\%)

Fig-12: Effect of coating in decreasing sound levels

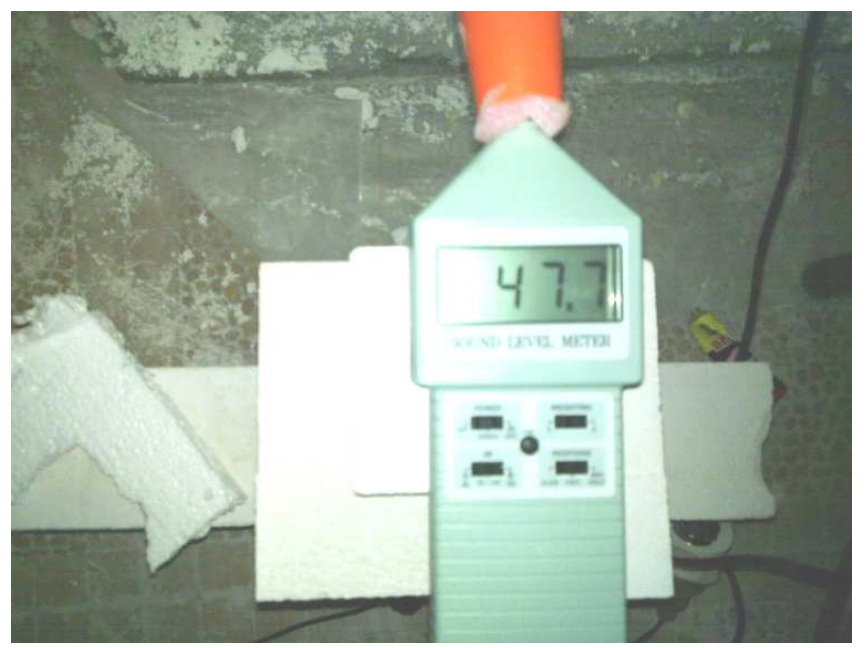

Fig--13: Measured sound from the outside of AAC panel by sound level meter

The results of laboratory tests can be only used in preliminary assessment of sound reduction performance of walls made of aerated concrete in relation to acoustic requirements for partitions. Sound insulating performance to a large extent depends on structural solutions used in the construction of internal and external walls, in consideration of sound propagation principles within buildings. Moreover, the workmanship quality of structural solutions is equally important from the viewpoint of sound reduction properties. It would be also advisable to continue to investigate the sound reduction properties of innovative structural solutions which have the potential to improve the insulating properties of AAC walls.

\section{CONCLUSIONS}

Results indicated that increasing humidity condition inside the chamber causes reductions in average sound transmission losses of AAC wall. Also for different sound levels, sound transmission losses change parallel to sound levels inside the chamber and it is understandable that there is no resonance in acoustic properties of AAC walls.

Considering advantages of AAC in energy savings and cost effectiveness are beneficial to find the way for counteract humidity intrusion effects on AAC's physical and mechanical properties. According to test results coating is the most important factor for improving resistivity of AAC walls, and these factors help AAC walls to keep their mechanical and physical properties against humidity.

With its closed air pockets, AAC can provide very good sound insulation. As with all masonry construction, care must be taken to avoid gaps and unfilled joints that can allow unwanted sound transmission. Combining the AAC wall with an insulated asymmetric cavity system will provide a wall with excellent sound insulation properties

\section{REFERENCES}

[1]. Zapotoczna-Sytek G., Malolepszy J. (2008), Zrównowawony Rozwój, A Process Wytwarzania I Stosowania Elementówz Betonu Komórkowego, Dni Betonu Tradycja I Nowoczesnosc, Wyd. Polski Cement, Kraków, 867-878.

[2]. PN-EN 771-4:2004/A1 (2006), Specification for Masonry Units, Autoclaved Aerated Concrete Masonry Units.

[3]. PN-B-02151-3 (1999), Building Acoustics - Noise Protection of Apartments in Buildings - Sound Insulation in Buildings And of Building Elements - Requirements.

[4]. ISO EN 717-1 (1995), Acoustics - Rating of Sound Insulation in Buildings and Building Elements - Part 1: Airborne Sound Insulation.

[5]. Narayanan N. and Ramamurthy K. (2000), Structure and Properties of Aerated Concrete. Building Technology and Construction Management Division, Madras: Department of Civil Engineering, Indian Institute of Technology.

[6]. Wittman. F. H. (1992) Advances in Autoclaved Aerated Concrete. Zurich: Swiss Federal Institute of Technology, P. 21.

[7]. TS EN 679 Gazbeton - Basınç Dayanımı Tayini, Determination of the compressive strength of autoclaved aerated concrete

[8]. TS pr EN 1353, Gaz ve Kopuk Beton Rutubet Muhtevasi Tayini, Determination of Moisture Content of Autoclaved Aerated Concrete

[9]. Warnock. A.C.C. (1985), Fundamentals of Building Acoustics, Canadian Building Digest, p. 236. 
[10]. Sasan Somi, (2011), Humidity Intrusion Effects on Properties of Autoclaved Aerated Concrete, M.Sc. Thesis, Eastern Mediterranean University, Gazimağusa, North Cyprus.

\section{BIOGRAPHIES}

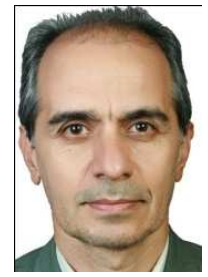

Dr. Eng. Abdullah KEYVANI received the $\mathrm{Ph} . \mathrm{D}$. degree from University of Hokkaido in Japan, in Civil Engineering in 1998. Currently, he is Assistant Professor of Civil Engineering at Azarbaijan Shahid Madani University in Tabriz, Iran and teaches Advanced Concrete Structures, Design of Concrete Structures and Concrete Technology \& Laboratory. $\mathrm{He}$ is also a Senior Consultant Engineer of the East Azarbaijan Regional Water Corporation. His research interests are in the area of Design, Construction and Quality Control of Reinforced Concrete Hydro Structures.

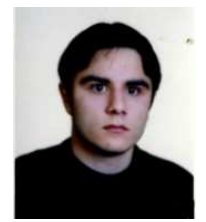

Sasan SOMI is a civil engineer and was graduated in Master of Science in Civil Engineering from Eastern Mediterranean University in 2011, North Cyprus. He currently works as a supervisor engineer in a construction company of underground line of

Tabriz city in Iran.

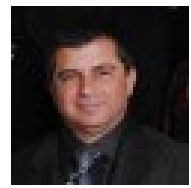

Professor Özgür EREN is chair of Civil

Engineering Department in Eastern Mediterranean University in North Cyprus. He currently teaches various Concrete courses and supervisor of many Ph.D and MSc. Students. 